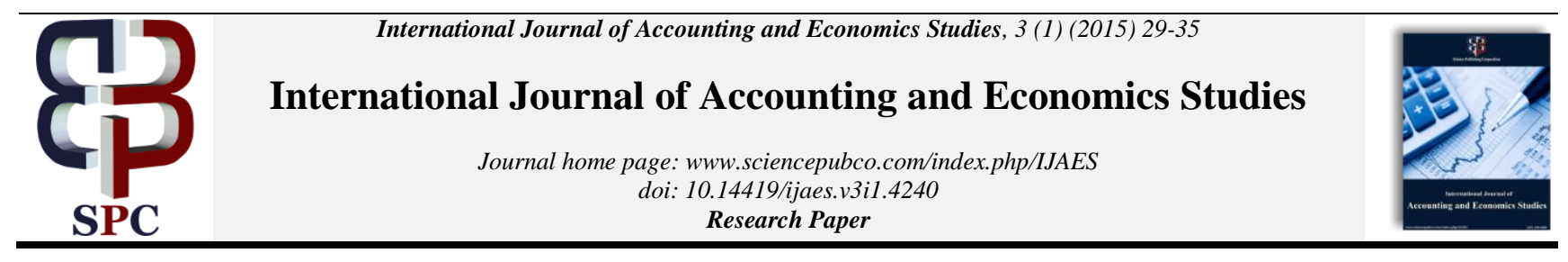

\title{
Check cloud computing profession in comparison with traditional brands
}

\author{
Shaban Mohammadi ${ }^{1 *}$, Ali Mohammadi ${ }^{2}$, Mohammad Mehmandoost $^{3}$ \\ ${ }^{1}$ MA Student, Accounting, Hakim Nezami University of Quchan, Quchan, Iran \\ ${ }^{2}$ Department of Accounting, Quchan Branch, Islamic Azad University, Quchan, Iran \\ ${ }^{3}$ Department of Accounting, Payam Noor University of Quchan, Quchan, Iran \\ *Corresponding author E-mail: shaban1362@gmail.com
}

\begin{abstract}
Information needed to perform computing tasks can justify the need for us to technology. accounting knowledge is significantly changing and improving. financial companies - large accounting and professional services organizations are increasingly moving toward technology. the computational intensive tasks for companies without expensive hardware and software. Science and technology of cloud computing or cloud computing are a hot topic right now is the accounting profession. the purpose of this paper is to examine the impact of cloud computing on the accounting profession, along with a review of all aspects of this technology compared to the traditional brands.
\end{abstract}

Keywords: Cloud Platform, Cloud Computing Technologies, Financial Reporting.

\section{Introduction}

Now evolutionary computation is such that it can then water, electricity, gas and telephone as an essential element fifth assumed. In this case, users are trying to according to their needs, regardless of whether a service where located or how it will be delivered to achieve. the variety of computing systems is presented attempt to provide such services to users. some of the, (cluster computing) are: cluster computing and more recently, cloud computing (grid computing) grid computing (cloud computing). these two major categories of computing systems, in applications require a high volume of calculations is used. these two categories, including computing cluster (cluster) and grid computing (lattice or grid, grid), respectively. the third category is structure and application of cloud computing is different.

\subsection{Cluster computing}

Computing cluster in a cluster computer, a group of free computers that work together and in many ways PC can be viewed as a complex behavior. components of the cluster computers usually are connected to each other through the network. clusters usually speed, create redundancy to increase accessibility continuous and secure the position of the error configured.

\subsection{Grid computing}

Grid computing is further confused by cloud computing; two things are quite different. Grid computing, several sources' computers in a network to work concurrently on uses on an issue. This is mostly used. When will be considered a scientific or technical Problem. Famous examples Is. Home the search for an extraterrestrial intelligence project the project will allow people around the world until the unemployment, the search for signs of intelligent computer extraterrestrial be used.

\subsection{Cloud computing}

The persian to the cloud, (cloud computing) term cloud computing and cloud computing have been translated, structural make it look like a cloud mass that users can to access applications from anywhere in the world are. So, the next cloud computing instead of the term cloud computing will be used, can help network, as (Virtuale machines) virtual machines a new method for creating dynamic new generation of data centers considered. thus, in the world of computing is rapidly software development is going to run it on Individual PCs, as a service to millions consumers are. as mentioned above most of the time was wrong grid computing to cloud computing will. To prevent the error from the comparison of the two offers.

\subsection{Comparison of cloud computing and lace}

The major difference is that the computing cloud computing and computing net screen. a huge project is divided among multiple computers, the resources it employs.

the growing popularity of cloud computing is that it represents avariety of technologies are being used more and more for Popularity as one of the new Internet technologies like any computer innovations quickly to the business world accounting also opens the way. Therefore, this paper attempts to address this issue and the impact of cloud computing technology on the accounting profession check. The paper is organized as follows: In section 2, the cloud, the Section 3 reviews the accounting profession cloud computing technology, the section 4 . Finally, section 5 is to evaluate and compare models and technologies conclusions and suggestions for future work are presented. 


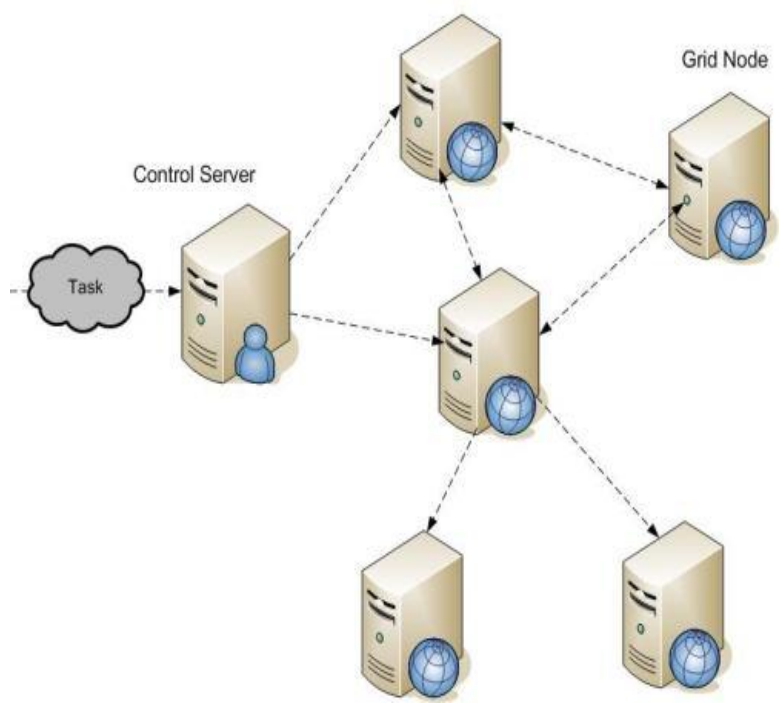

Fig. 1: View of Computing Net

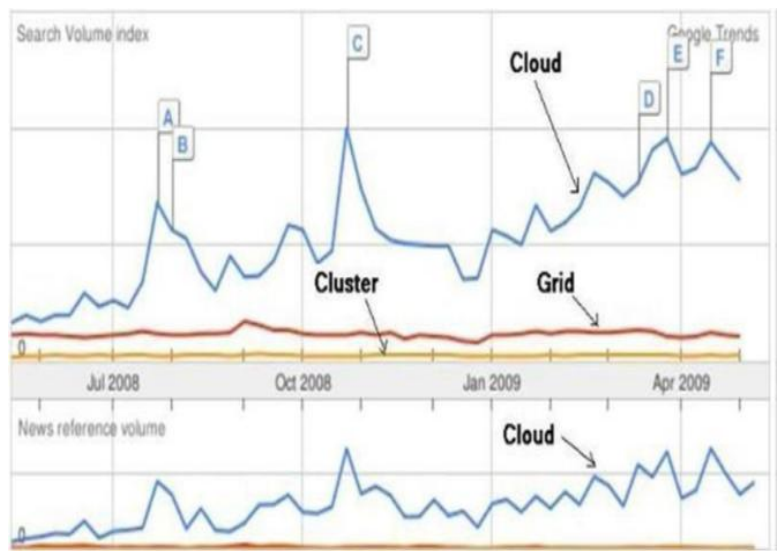

Fig. 3: Check The Google Cluster System Acceptance, Net and A Cloud in the Years 2008, 2009.

\section{What is cloud computing?}

With the development of computer equipment and dependence most of us in the digital world, companies have to are seeking to accelerate the promotion of their services to customers. Naturally, any company that is faster and better services. Its users will be the winner of this field. In this cloud, the issue by large companies and looking extremely small and huge investments have started on it. Indeed, what is cloud computing its definition. Before the definition of cloud computing, the better the meaning of the word "cloud" be clarified. The cloud is a metaphorical term that refers to the Internet. And a system which may ultimately distributed and parallel computers connected through a series of virtual and physical form different levels of service to one or more computing resource ally based on agreements between service provider and consumer provided services provided. In general, it can be said that cloud abstract image of a network, and the great bulk of it is unknown, it is not clear how consists of processing resources. Every dimension of time and space components are not known, as well as hardware and software instead, this software is not apparent mass. but the definition of cloud computing is to say that, since it now it has been accepted for presentation, however, most experts on the part of the definition of this phenomenon is vote. and who defines cloud computing wikipedia: "cloud computing is a computing model based on large computer networks the Internet is the new model for the supply, delivery and consumption IT services (including hardware, software, data, and other shared computing resources) by using the Internet that (Rimal et al. 2001). Cloud computing to provide information technology solutions to the manner similar to utilities (water, telephone, electricity, etc.) suggests. Just like electricity, water and gas. You have the EquipmFigure 1: View of computing net

But cloud computing has allowed several small computer programs can be run simultaneously on multiple computers.

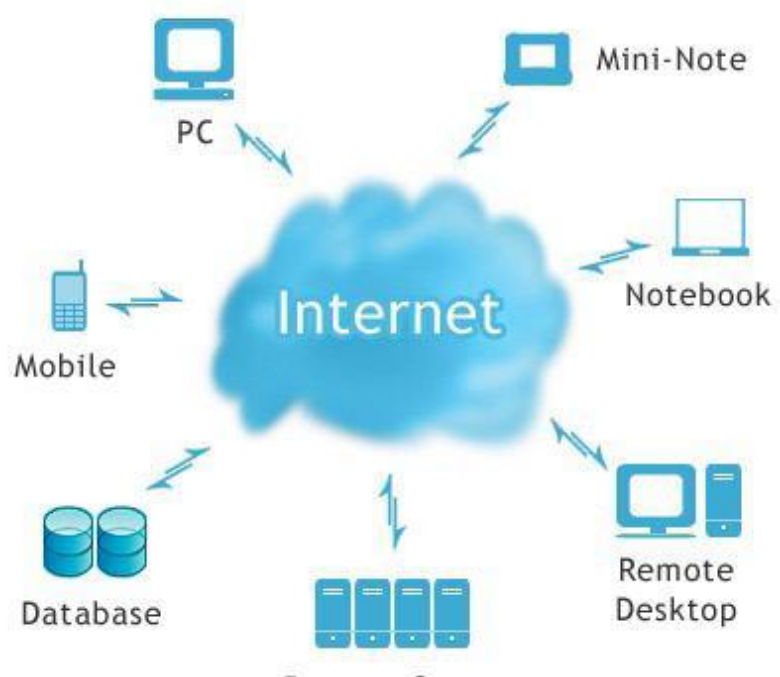

Remote Server

Fig. 2: View of Cloud Computing.

Computing net can only be used for applications who have the ability to run in parallel, but in computing there is not a cloud in the corresponding fields. In a concluding generally, it can be said that the ultimate goal of cloud computing services to provide the highest end users are. The purpose computing net calculation heavy and above the net. (Velte et al. 2010)

\subsection{The acceptance of a variety of computing}

The popularity of the mentioned three different types of calculations, the google's search engine visibility is evaluated the result is shown in Figure 3. This study shows that cluster computing is now more than two other less popular, computing the second screen Is, and cloud computing are far from Increase people's attention more.

Electricity, gas and water use at home or work you do not need a generator of electricity, gas and water system at home you, but for a certain fee, you rent it. Now if you use more or less, the cost of consumption, you will pay for itself, without the hardware components be aware of the services and. America cloud NIST «National Institute of Standards and Technology» It is also defined as: "Cloud computing is a model for an easy access on user demand through the network to a set of processing resources are subject to change and configuration (eg, networks, servers, space Storage, applications, and services) that can be accessed with minimal labor or intervention providers Service provided or to be released soon. " The cloud model, and improves the availability of five the important characteristics, three service models, and four deployment models (Rimal et al. 2001).

\subsection{Characteristics of cloud}

Computing features include a choice of cloud-based service request, broad network access, resource integration, flexibility, speed, agility, scalability, high reliability and service-oriented is . 


\subsection{Models of Service cloud service models or types of services}

In Indeed, in this kind of technology on the Internet Be made available to the users. All cloud services can be classified according to these sources, and usually refer to "the as a service "and used words are given. Based on ANSI NIST cloud computing services offered in three forms SaaS, (Software as a Service), IaaS (Infrastructure as a Service), Paas (Platform as a Service).

\subsubsection{Software as a service (SAAS)}

Cloud services, applications or software as a service, Software as a service over the Internet, and thus the need to install software on the client computer and to make it easier to maintain and support. Because the customer cloud infrastructure, network, servers, operating systems, space manage or controls the underlying storage or application does not. This is primarily a software application commercial known.

\subsubsection{Cloud platform as a service (PAAS)}

Cloud platform services, computing platform (often on infrastructure implemented cloud and cloud applications feed) into whether the service. in this model, instead of software, platform (platform) as a service. The platform as a service, the software can be used without the cost and complexity of buying and management of hardware and software (such as Java, Python.NET, .NET, Etc.) and provide web hosting services expanded software developers to create new applications or previous development programs need to be developed spending.

\subsubsection{Cloud Infrastructure as a Service (IAAS)}

Cloud infrastructure services or infrastructure as a service, Computer infrastructure (typically a physical or virtual platform a) to provide the service. Users instead of buying Hardware, software, data center space or network equipment, all this infrastructure as a fully outsourced service buy. Usually based billing services (outsourcing) the utility computing model (water, telephone, electricity, etc.), the amount of resources used to be exported and therefore, costs, reflecting Activity (Velte et al. 2010)

\subsection{Cloud computing deployment models}

From the above discussion, it can be said that cloud computing model that is demand-based services to end users offers. Clouds in the physical infrastructure used, where the clouds (virtual Infrastructure) software used to deliver a service to customers is. Such infrastructure and middleware in terms of service, administrative areas and meet different users. The establishment the cloud is divided into three types, namely: public cloud, private cloud, hybrid cloud.

\subsubsection{Public cloud}

Public cloud model is the most commonly used. Data centers made by public cloud providers are quite are large, consisting of thousands of servers with high-speed networks are. These clouds to support thousands of users in the area are public. Public clouds are the most popular Google appengine, Amazon web Services microsoft azure during this deployment, public cloud services in a "pay - per - use rates" are available. A public cloud can offer any of the following services: PaaS, SaaS, IaaS.

\subsubsection{Private cloud}

While public clouds are quite welcome and Solutions and implementation of such an infrastructure to reduce costs provides information technology, but there are still scenarios where organizations may wish to own clouds hold to your specific needs to provide. For example, industry many health care and the confidential- ity of medical data can't be stored in public infrastructure, maintaining a. thus, and private clouds within an organization in order to service the information technology bases for internal users provided. Private cloud services, more in control of the making the offer. Enhance security and flexibility improved the service for which access is limited to one or several organizations. Such private service, restrictions it is the inability to develop a scaled based on demand provides software for end users, while this (scaled on demand) by cloud services public done. An organization can machines the user needs to buy more, but it does not work public cloud can be done quickly. The rise development combines the advantages of both public and private cloud in organization accessible.

\subsubsection{Hybrid cloud}

These clouds are a combination of public and private clouds, but activities and tasks for each of the different clouds will smell of each to be independent of its environment by combining multiservice cloud, public cloud users the ability to find that the transition to the Stay away from the problems and limitations of the past and make it easier to Security and infrastructure systems are aristocrats. in this Infrastructure and computer models ride on a cloud environment, they can be two or three individual or group or public form, but this would be possible with other environment's data exchange.

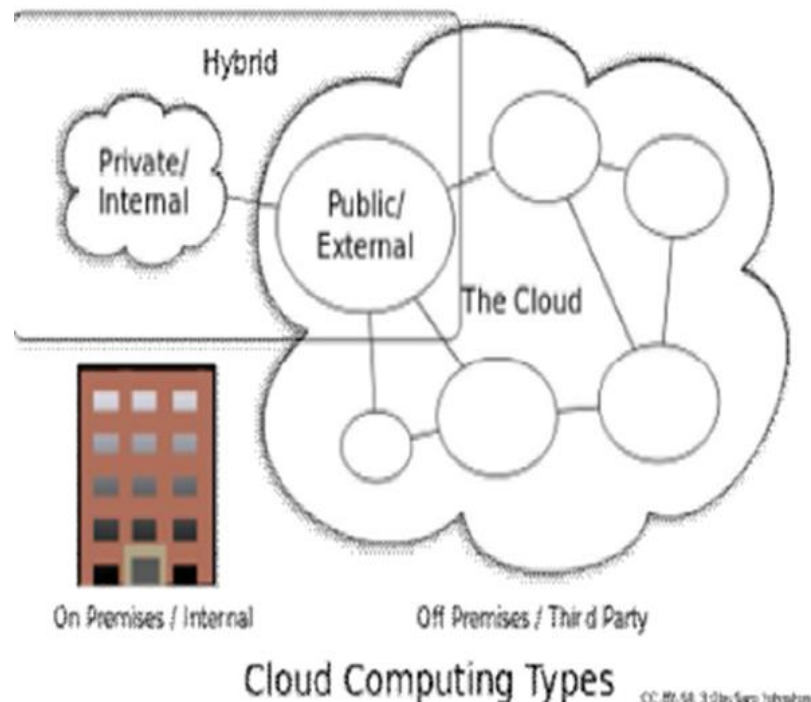

Fig. 4: Types of Cloud in Cloud Computing.

From the above we can find out who is trying to cloud computing model with minimal manpower and resources needed to reduce costs and Speed up access to data, answer the needs of users various fields.

\subsubsection{Scope of application of cloud computing}

Although cloud computing is not entirely new, but the technology is everywhere is present. Over the past few years as quickly human aspects of life such as education, telecommunications, banking Internet banking services, including online bill payment electricity, water and gas ... order online video, online reservation, internet shopping, Internet voice and video calls, chat, Search the web world, social networking and e-mail, games computers, academic research, etc., affect the and especially by a change in the functional areas of management web content, document management, financial management, email management, e-commerce business models in line with the accounting Has evolved. In this section, an attempt is the accounting profession in the cloud. 


\section{The impact of cloud computing on account- ing first}

Let's be clear that the term accounting. The to achieve this objective a definition of accounting offered.

\subsection{Definition of accounting}

Accounting is called the language of business, because it is through the provision of financial reports, information on economic entities in Stakeholders and interested parties alike. This includes directors, owners, investors, creditors, financial institutions and such is the state of the economy. From another perspective of accounting, accounting information system called accounting Information system will be remembered that the system processing of financial information relating to events affecting the organization's business units and reporting of these events is designed for decision makers] accounting, "a statement of basic accounting theory," according to the process of identifying, measuring and reporting financial information to make informed decisions by users of information. Statements mentioned in this definition is followed by can be "accounting", based on a comprehensive view "Financial information" be considered. In looking at these definitions can be understood that all companies and financial institutions ranging from a small company and institution the country's largest manufacturing plant and accounting information need. For For example, a person is in a financial Investment Company does not want to face the situation accounting and finance company knows it. So, to answer if the financial needs of mankind, accounting software was designed.

\subsection{Accounting software application models}

Today the use of accounting software pro has three options are: traditional model of software accounting desktop, cloud models and hybrid models.

\subsubsection{Traditional model}

To understand the traditional process models and software applications accounting for traditional desktop computer, consider a company that for all your employee's computer and operating system. It's different on each install. In this Model for employees, companies should be soft accounting software as a product purchased on they and all their computer systems company; they put in the hard drive which causes are numerous. Why and how? The company has employees usually are files that need to be interact with each other to process these files, such as a file consider a text report that is due by five people edited. One's user? If the company wants the job sharing what to do? So we should give money to install a license on five buys a computer and then install it on every single one. First, this requires more expensive and, secondly, should the software installation and nearly five times if any of the computers should never fail to have separate software problems to solve. Apart from the need to ensure that all computers have the hardware required to install the software the software has a firmware upgrade to version above shall be considered as if the disk is corrupted member's disk, millions of bytes of data in one eye disrupt the disappears. Let us examine the issue from another perspective. If memberships want to edit a text file or picture that you need software, the software must be purchased and the amount on their computer and then be forced to travel what happens? Can naturally your desktop computer as a result, he never takes the software can't be installed use on any other computer. All of the above, including the costs and constraints of time and place is applied, the problems that caused the company large and small cloud operating model and accounting services the cloud over them, because it will be the end to the nightmare. Several users instead of installing software on multiple computers, only one runs and loads the software once and for all people through an online service to which they have access.

Three -3 cloud operating model

It is currently a hot topic in the world of cloud accounting accounting. Accounting cloud, which "online accounting" they say, like bookkeeping works users are installed on your computer, except that the soft cloud accounting software on the servers' provider online services ", is applicable to any number of users and companies and organizations can use their web browser, on Internet access it. This means that you as a user company or organization, each time an Internet connection is able to access their company's finances from anywhere and any device you're using. Accounting firms and organizations through cloud users online accounting software applications, "presented Software services "in the cloud have access, in fact, the use of accounting software in a similar model (software as a service) provider of online services to buy. They for software, hardware or network not pay, but computing power and software services needed to purchase. With this interpretation, if accounting professionals to conclude cloud computing, outsourcing in the old drink new bottles and many have gone astray. Cloud-like business process outsourcing, such as the purchase of one or more than one offer outsourcing service organization. A key difference in what the buyer is usually a process of outsourcing work is defined as the average salary in what is cloud computing infrastructure and service purchased a fan, some or all the information that may do not rely on it. Basically the information technology infrastructure in all areas of business, including accounting firms under effects. It seems logical that here the necessity of using cloud computing in accounting too.

\subsubsection{Operational models combine}

Hybrid model consisting of multiple internal and external provider, It is a good option for most businesses, because in this, pattern is noncritical and external sources of information in the cloud general processed while the service and the critical control keeps the private cloud have. Therefore, organizations can use information technology infrastructure. In order to protect their data and efficiently use to keep sensitive information private cloud and anywhere yi automatic scaling up resources needed for public clouds benefit. These resources or services temporarily at maximum load Lease and are then released. $4-3$ need cloud computing model in accounting the first and greatest changes in work organization and will the Internet. The internet changed the way performance businesses and professions upside down, these changes far beyond ecommerce, because trade a byproduct of the Internet. What caused the change fundamental processes and culture organizations, the Internet? While the Internet, information technology is the most responsible for changes in professional practice, has no role commercial software package enterprise resource planning systems (enterprise resourse planning) ignored. Enterprise resource planning systems are doing is all the data are collected in a central source so that access to information is the key for members outside the organization much easier. Obtain a phase Enterprise resource planning systems will require greater coordination internal system resource planning systems Suppliers and customers, which creates a system resource planning several companies in. enabling technology for the development of such systems, cloud computing model of the Internet. How technology "here may be, the question is who Information related to the accounting and why the models will need to change? The answer is that investors and creditors as part professional members are looking for alternate sources of information to assess the performance of the company. While they still have use of the information in financial statements are audited, this information is only available periodically on the basis of past accessibility. Therefore, it is reasonable to assume that the expected they are also available for access to key information on the company's internal information systems will be more. this For some people with completely different expectations of disclosures that by The daily for free through sites offerings are. It's just a simple financial records and financial statements audited (periodi- 
cally on the basis of the past), and it is available to the public via the Internet. The need for investors ask impatience with current information about the company's financial status are not resolved. Therefore, the information provided for making minor unless otherwise new model to provide financial information timely and correct this need to be created, and this could be achieved through the cloud computing model. Using cloud computing model and the benefits it can make significant progress in achieving largely through the public information data base, especially the Internet as a result, decision makers should be able to Increasingly diverse and timely information for decision-making the. But accounting in computing technologies cloud can be utilized?

Five -3 accounting of cloud computing technologies

A number of technologies are effective for accounting in the cloud of the: databases (data analysis) expert systems (help deviation analysis, Lending and risk analysis) neural networks (as a tool to predict), storage Information (to provide specific information for users) decision supports software (to help decision-makers to the data analysis and the impact before a decision to support decisions their choice) superior communication (to improve the accessibility Information) digital signatures and digital certificates (possible provide continuous auditing). aI-based software (change reports. In accordance with the terms possible) data mining and analytical processing time Intelligent agents (in order to analyze information and contributing to the decision) -1 for data transfer) XBRL reporting language 2 . accounting for the world wide web to facilitate - access to information for investors and analysts, 3- to extract and evaluate the right to use the data, 4 - comparison of corporate financial reports. each industry by creating consistency in the classification of financial data). After considering the nature of the cloud computing model, combining traditional and necessitates the use of cloud computing technologies in accounting and effective cloud accounting chance has come to two main models cloud tradition have its advantages and disadvantages compared to the expression is to determine whether the cloud computing model as a remarkable new technology in accounting or not. 4. Comparison of cloud computing and traditional although cloud computing is an emerging technology in the literature, a lot of work compared with the traditional model of cloud computing that each of the different points on this topic paid. Some researchers believe that the companies to gain application-specific software or operating system available the Internet or outsource all IT departments. Through the use of their IT operations models traditional and entry into new environments by providing Party service providers through the cloud service models.

As the images are cloud applications, web site is designed for deployment, multiple (to be delivered by a vendor to customer), and users of spatial processing power provided by the seller to share. In the cloud, accounting, and business is business the website is easy to do, in this case you need to buy, Implement and maintain technology infrastructure internal server destroys. Unlike the traditional software distribution and has a normal deployment requirement. Another difference between the two models is that traditional service providers their services according to customer's contract offer long-term contracts are typically one year or more and have properties are relatively constant. But cloud computing service providers, such as water or electricity to provide, any level poses qrardard- ratio demands services, and the proportion of each service and programs offered charge. however, it assumes you need to use the time in a day, leading to cost reduc ation for that day. So we can say that the main advantage of cloud computing, reducing costs for its users.
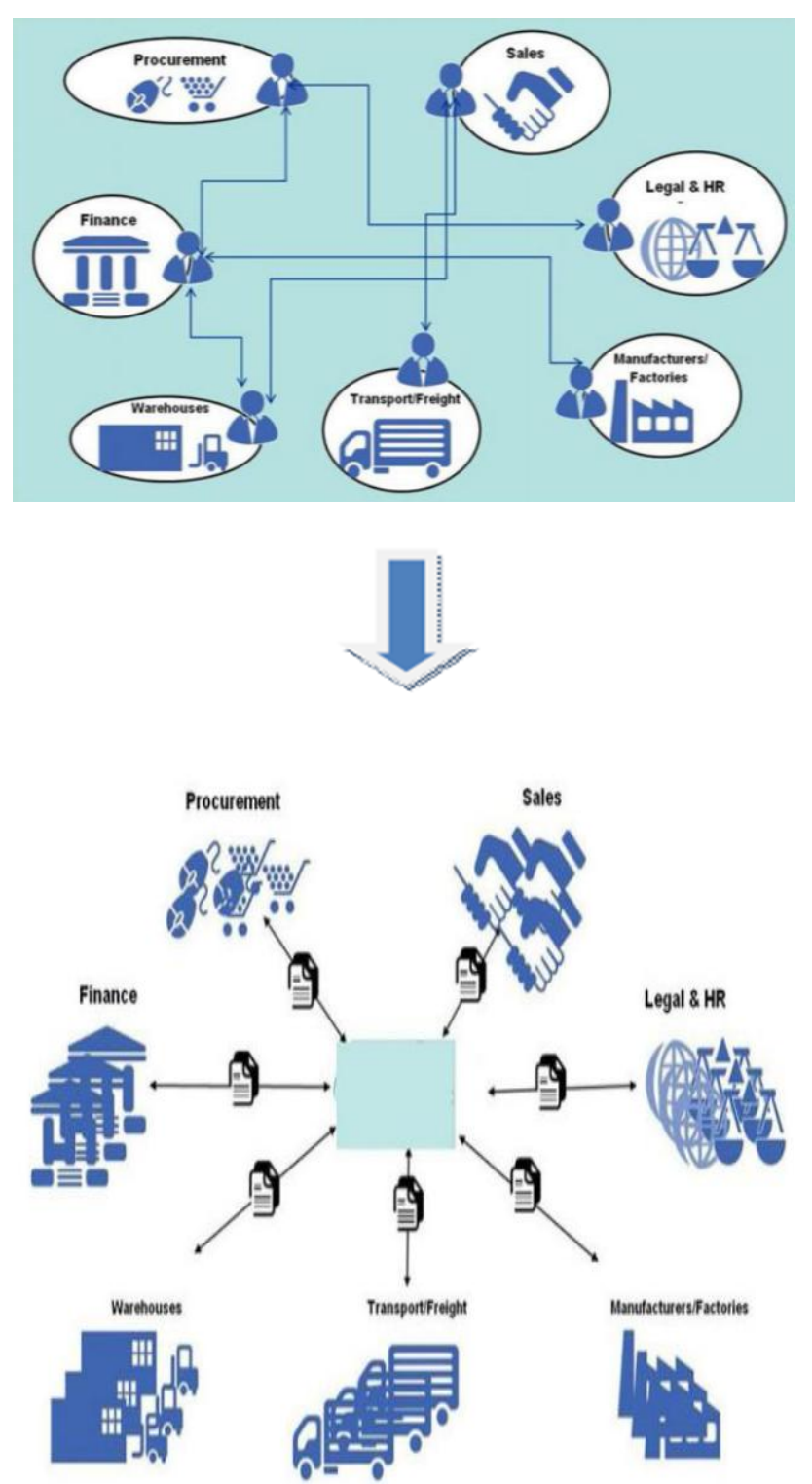

Fig. 5: Operational Cloud Model

\subsection{Benefits of cloud computing in accounting}

The benefits of this new technology are:

Acceleration time.

No doubt if the accounting work using online services and cloud computing can be done, will speed up the letters to people and get them will.

Follow without physical presence.

Many times before is that a person is on duty or on leave. If Internet-based systems, this one can be in anywhere it is to communicate via the Internet to letters respond or refer them to other people. Connect to other computer systems

Many of the letters the impact on other systems left office. As for example, a request to leave the system affects the rights, and a purchase invoice will affect the storage system over a impact will affect the reported cost accounting system. Thus it can be seen that if a fabric system using online services, these effects are easily implemented system is.

Availability.

Dare to be anywhere today the world where you can find an Internet connection. So in if you're using a cloud computing system, none of the employees you are out of your reach, and you can easily or part of a purchase order to the officer to another country price and specifications are sent or her machine tries asking your requirements.

Low-cost computers for users 
You need a computer Intensive and thus costly to implement webbased applications you do not need, because the programs are running in the cloud. Improve performance. Since the applications in the cloud are, with few large programs that the computer's memory occupies, users can more performance from your PC See her increased computing power.

When you work in an environment cloud computing logged on, the power of the cloud and get all the the simple power of a desktop $\mathrm{pC}$ is not limited to, but can functions like a super computer to do and the computer power server benefit.

Store unlimited capacity building.

To the cloud, you have the system can be connected to the cloud and documents on heterogeneous systems may no longer be an available note.

Improve matching between document's formats.

You do not need to worry about documents that you create on your machine to be compatible with other operating systems and machines. All documents in the cloud by a web-based application are created by the program other cars are also accepted. collaboration easier. Sharing documents directly to cooperation the evidence leads. For most users, these are the users can collaborate on a document or project that is so important is. It is easily possible with cloud computing.

Universal access to documents.

With cloud computing business of any Person (or another document in the document in the computer home office) cell is always available in the cloud. Where the document required it was just an Internet connection to connect to cloud computing, and the document is available.

Access to the latest version.

When you edit a document where else where, you have access to the latest changes, because the document is stored in the cloud. Since the total cost for Companies and individuals are important in the cloud computing model, low cost. The main advantage is that it can be considered by companies. Despite the numerous advantages of cloud computing, it has some disadvantages is.

Two -4 disadvantages of cloud computing in Accounting

There are a number of reasons that you may need to remove not their use of cloud computing. Some of the reasons are as follows:

It requires a constant Internet connection.

To connect to computing cloud need to connect to the Internet without any access documents in the cloud and there.

It does not work well at low speeds.

Now with a contact low speed is not like a regular phone service computing cloudy to good use.

Security.

Most users rely on cloud computing in accounting concerned socialization services and security systems and data. All data well and simply stored in the cloud, but there may be data. Including confidential files are stored securely in users or service is disrupted. therefore, the relevance of socialization computing Cloudy with clear internal controls and audit.

The lack of a comprehensive understanding of control.

Lack of control prevailing on the Internet cloud systems suppliers, with Issues of data, ownership can expose users the higher the risk So at this point professionals Sas number of audit and accounting should cloud users 70 notify.

\subsection{Move to cloud computing}

It is anticipated that during the info world news a decade later, it will focus on the world of information technology its main Internet services (cloud) focus. Statistics show that of previous years and started offering cloud services. It was a move towards a more continuous process clouds there. Various reports have confirmed the continuation.

\subsubsection{Basic statistics}

According to one report, Gartner group estimates that SaaS sales in 2010 reached Bh9 billion 15.7\% increase compared to 2009 , and increased \$ 10.7 million In 2011, an increase of $16.2 \%$ over the year 2010. Gartner Group estimates that well over 10\% Sold around the world in applications as SaaS have. It also estimates SaaS in the world in 2014; more than $16 \%$ applications are included. A report published by the analytical center tech market view predicts, the market value of cloud computing in the UK 2010 was $£ 5.8$ billion in 2014 to 10.4 Billion pound increase.

\subsubsection{Accounting statistics}

LaFollette predicts that in the next 10 years approximately there is no software applications based on the traditional model found. A recent survey of more than 1,000 companies accounting by AICPA marketing arm - CPA2Biz Showed that $70 \%$ of respondents to increase their use of Web-based applications in the next six to 18 months. Planning. As part of the "confidence-building business applications consulting CPA2Biz has negotiated with some cloud vendors." These include companies, companion, Bill.com XCM and Paychex, Intacct. Russell Evans claims that the current software Cloud-based accounting by a large and growing part of Accountants and accepted two companies, about 14\% Companies and 23 percent of accountants (especially young people) in Australian cloud-based software to manage account were selfabsorbed. Figure 3: the adoption of cloud computing by accountants and companies.

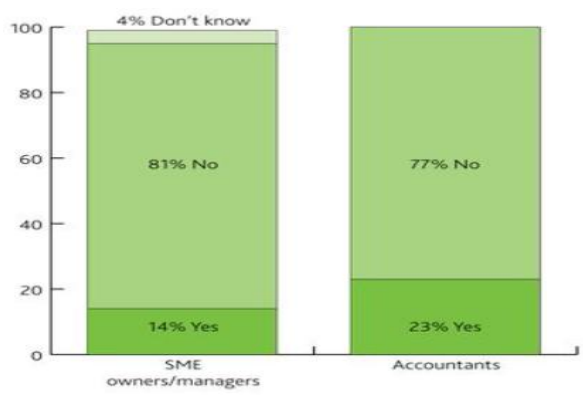

Fig. 6

The survey says that $60 \%$ of $77 \%$ of accountants today cloud systems are not used, probably within the next two to three will do it next year. So, we quickly, we are approaching a point where the cloud accounting software for ubiquitous services that this leads to a large change in the next few years will. The statistics for the accounting profession what could have is? According to the data, it can be said that the move accountants have not started in the cloud, and your company's businesses are at risk. Therefore, a clear need for accountants are taking the initiative in the solution control their cloud-based clients in your company make the trip with them. Thus, the central roles managements of their clients' accounts are safe andCan again provide strategic consulting services with more value focus.

\section{Conclusion}

In the 21 st, century saw the rise of portable devices tend style for access to Internet services rather than PC are. Since such devices and processing facilities are not strong, then who will provide processing power? Reply to this the question lies in the cloud. The main driving force behind cloud computing Include wireless networks, reducing storage costs and improving the software for online processing. With facilities cloud computing cloud service customers will be able to load more inject into your system, reduce costs, experience, new services, and remove unused capacities them. In summary, the following equation is derived cloud. According to the needs of the users of accounting information and the disadvantages of the current model (traditional) application of information technology, determined accounting that eventually led to the timeliness finds. So it is suggested that the accounting system steps in this direction, accounting and security systems audit 
in accordance with the design and development of new technologies and accounting and financial reporting with the rapid changes in the world keeping the business generated.

Acknowledgement

With all the efforts of Mis. Soheyla Rafienia in preparing this article, I would appreciate the help.

\section{References}

[1] Velte AT, Velte TJ \& lsenpeter R.E (2010) " Cloud Computing: aPractical approach", McGraw-Hill Companies,ISBN: 978-0-07162695- 8,pp-16, 27, 31\& 32 .

[2] Rimal B.P, Jukan A, Katsaros, \& Goeleven Y (2011) "ArchitecturalRe quirements for Cloud Computing Systems: An Enterprise CloudAp proach", Springer, Netherlands, Journal of Grid Computing,Volume 9, Issue 1,pp 3-26, March. http://dx.doi.org/10.1007/s10723-010-9171-y.

[3] "Cloud Computing - A matter of survival for the accountingindustry? " $\mathrm{CCH}$ Research Report, $\mathrm{CCH}$ CollaborativeSolutions, division of Wolters Kluwer, April 2013. Available

[4] Brewer CW,(1994) "Origins Of The Accounting Revolution", Accounting Sam Huston University, No. 94-03.

[5] "Defining Cloud Computing for Business Users", Posted Octo ber12, $2009 . \quad$ Available online. at:http://socialmediatoday.com/index.php?q=SMC/13214.

[6] D. Falkenhagen, J. Talley, " Technology Spotlight: Accountingfor Costs Associated With Cloud Computing ", DeloitteDevelopment LLC. Issue 3, pp-7, October 2012.

[7] Plummer D (2012). "The Business Landscape of Cloud Computing ", Gartner Inc. Available online at:http://www.gartner.com/technology/about/ombudsman/omb_guide. (Last access: August 2013)

[8] "Find Value in the Cloud: 11 Useful Solutions for AccountingFirms ", cchgroup.com, 2013. Availableonline http://www.cchgroup.com/opencms/opencms/web/TAA/Microsites/ax cess/PDF/Find-Value-in-the-Cloud.pdf. (Last access: August2013).

[9] Mell P, Grance T (2001), "The NIST Definition of Cloud ComputingNa tional Institute of Standards and Technology," Gaithersburg,MD 20899- 8930, pp-2 \&3, September.

[10]Buyya R, Yeo CS \& Venugopal S(2008) "Market-Oriented CloudCom puting: Vision, Hype, and Reality for Delivering IT Servicesas Compu ting Utilities", Manjrasoft Pty Ltd, Melbourne, Australia.

[11]Aggarwa S, McCabe L,(2013) " How TCO Benefits Make CloudCom puting No Brainer for Many SMBs and Mid -MarketEnterprises ", SMB Group, Inc.,pp.2, February 2013.

[12].Araov S,Raonk, N Kumari EK,(2005) " Cloud computing: AnOverview Journal of Theoreticaland Applied Information Technology, JATIT, PVP Siddhrtha Institute, Vijayawada, India. 